\begin{tabular}{|c|c|}
\hline Title & Effects of metal cations on mild steel corrosion in $10 \mathrm{mM} \mathrm{Cl}$ - aqueous solution \\
\hline Author(s) & Islam, Md. Saiful; Otani, Kyohei; Sakairi, Masatoshi \\
\hline Citation & $\begin{array}{l}\text { Corrosion Science, 131, 17-27 } \\
\text { https://doi.org/10.1016/.corsci.2017.11.015 }\end{array}$ \\
\hline Issue Date & 201802 \\
\hline Doc URL & http:/hdl .handle.net/2115/76657 \\
\hline Rights & $\begin{array}{l}\text { () 2018. This manuscript version is made available under the CC-BY-NC-ND } 4.0 \text { license } \\
\text { http://creativecommons.org/icenses/by-nc-nd/4.0/ }\end{array}$ \\
\hline Rights(URL) & http://creativecommons.org/icenses/by-nc-nd/4.0/ \\
\hline Type & article (author version) \\
\hline File Information & Saiful_A ccepted_Manuscript.pdf \\
\hline
\end{tabular}

Instructions for use 


\title{
Title
}

Effects of metal cations on mild steel corrosion in $10 \mathrm{mM} \mathrm{Cl}^{-}$aqueous solution

\section{Author Names}

Md. Saiful ISLAM ${ }^{1)}$, Kyohei OTANI ${ }^{1)}$, Masatoshi SAKAIRI ${ }^{2)}$

\section{Affiliations}

1) Graduate School of Engineering, Hokkaido University, Kita-13, Nishi-8, Kita-ku, Sapporo, Hokkaido 060-8628, Japan.

2) Faculty of Engineering, Hokkaido University, Kita-13, Nishi-8, Kita-ku, Sapporo, Hokkaido 060-8628, Japan.

\begin{abstract}
The influences of metal cations on the corrosion of mild steel in $10 \mathrm{mM} \mathrm{Cl}^{-}$aqueous solutions were investigated by electrochemical techniques and immersion tests. Immersion tests and electrochemical impedance spectroscopy (EIS) results showed that $\mathrm{Zn}^{2+}$ has a significant effect on corrosion inhibition. Surface morphological inspection also showed the smooth surface of specimen immersed in $\mathrm{Zn}^{2+}$ containing solution. Analysis of X-ray photoelectron spectroscopy showed that $\mathrm{Zn}^{2+}$ was incorporated in the oxide films by making a strong bond. It is supposed that $\mathrm{Zn}^{2+}$ forms a very effective shielding film which can inhibit the electrochemical reactions, and consequently lowers the corrosion rate.
\end{abstract}

\section{Keywords}

Mild steel; EIS; XPS; SEM; Passive films 


\section{Introduction}

The stability of a metal when exposed to the environment depends on a multitude of factors that may vary greatly with the concentration of $\mathrm{Cl}^{-}$and $\mathrm{SO}_{4}{ }^{2-}$ of that environment. Mild steel is very popular and widely used metallic materials, and the corrosion of this steel is a serious problem in water supply, storage tanks and circulating water pipes etc., and the corrosion behavior have been studied by many researchers [1-3]. The corrosion rate of mild steel can be accelerated by the presence of the compound that may contains $\mathrm{Cl}^{-}$and $\mathrm{SO}_{4}{ }^{2-}$ [4-6]. Large amount of chlorine compounds $\left(\mathrm{Cl}_{2}, \mathrm{NaOCl}, \mathrm{Ca}(\mathrm{OCl})_{2}\right.$ etc.) are used as disinfectants in the waste water treatment and bleach for both domestic and industrial purposes. These compounds are also widely used to disinfect drinking water and swimming pool water, and to control bacteria and odors in the food industry [7-9]. Enormous amount of chlorine compounds is also used in the laundry to bleach and wash the cloths. Chlorine compounds are listed as a known poison and it has an adverse effect on corrosion of the pipe line of water circulation system and other metallic equipment that exposed in that environment, and these compounds are dissociated into $\mathrm{Cl}^{-}$and $\mathrm{OCl}^{-}$in the aqueous solution as following reactions.

$$
\begin{aligned}
& \mathrm{Cl}_{2}+\mathrm{H}_{2} \mathrm{O} \rightarrow \mathrm{H}^{+}+\mathrm{Cl}^{-}+\mathrm{HOCl} \\
& \mathrm{NaOCl}+\mathrm{H}_{2} \mathrm{O} \rightarrow \mathrm{NaOH}+\mathrm{H}^{+}+\mathrm{OCl}^{-} \\
& \mathrm{Ca}(\mathrm{OCl})_{2}+\mathrm{H}_{2} \mathrm{O} \rightarrow \mathrm{Ca}(\mathrm{OH})_{2}+\mathrm{H}^{+}+\mathrm{OCl}^{-}
\end{aligned}
$$

The oxide layer (passive film) of the steel is generally destroyed by the penetration of $\mathrm{Cl}^{-}$ in aqueous solution [4, 10-13]. Fig. 1 (a) and (b) shows the penetration and film thinning mechanism of $\mathrm{Cl}^{-}$into the oxide films [14-17]. After destruction of the passive films, the corrosion process starts with a coupled of electrochemical reactions $[1,2,18]$. Fig. 1 (c) shows the anodic reaction of metal dissolution (reaction (4)) and cathodic reaction of oxygen reduction (reaction (5)).

$$
\mathrm{Fe}(\mathrm{s}) \rightarrow \mathrm{Fe}^{2+}(\mathrm{aq})+2 \mathrm{e}^{-}
$$




$$
1 / 2 \mathrm{O}_{2}+\mathrm{H}_{2} \mathrm{O}+2 \mathrm{e}^{-} \rightarrow 2 \mathrm{OH}^{-}
$$

Otani et al. [18, 19], Kato [20] and Takasaki [21] investigated the corrosion behavior of mild steel by emphasizing the effects of metal cations in model fresh water, and they found that $\mathrm{Zn}^{2+}$ and $\mathrm{Al}^{3+}$ have ability to inhibit the corrosion. Mahdavian et al. [22] investigated the corrosion inhibition of mild steel by some zinc complexes in sodium chloride solution. Prabhu et al. [23] investigated the corrosion behavior of metal surface treated with a new organic chelating inhibitor in acid solution. Jin-xia Xu et al. [24] investigated the steel corrosion in saturated calcium hydroxide solution with metal oxides and nitrates. For this reason, the effect of metal cations on the corrosion of mild steel should be considered in the $\mathrm{Cl}^{-}$containing aqueous solution. The effect of metal cations on corrosion of mild steel in $10 \mathrm{mM} \mathrm{Cl}^{-}$aqueous solution is not fully understood. Therefore, it is needed to clarify the effect of metal cations on corrosion behavior of mild steel in the solution that contains $10 \mathrm{mM} \mathrm{Cl}^{-}$at an equal level of $\mathrm{pH}$.

Incorporation of the metal cations in the passive films would be significant to clarify the influence of metal cations on the corrosion of mild steel in the $10 \mathrm{mM} \mathrm{Cl}^{-}$aqueous solution. According to the Lewis concept regarding acid and bases, cations and anions act as acids and bases, respectively [25]. Further, acids and bases are categorized into 'hard' and 'soft' [26]. According to the hard and soft acid and base (HSAB) concept, soft acids react and form strong bonds with soft bases, whereas hard acids react and form strong bonds with hard bases. The metal cation hardness is based on the HSAB concept. The hardness of metal cations, $X$, is expressed as follows [18, 27, 28]:

$$
X=\left[X^{0}{ }_{M}+\left(\Sigma I_{\mathrm{n}}\right)^{1 / 2}\right]^{2} / 10
$$

Where $X^{0} \mathrm{M}$ is the electronegativity of the metal atom, and $I_{\mathrm{n}}(\mathrm{eV})$ is the ionization potential from the neutral metal atom to the given oxidized state, $n$. Hard acids and hard bases can form stable bonds. Hydroxyl groups, which are categorized as hard bases, are located on the outermost layer of oxide film of mild steel and metal cations with large $X$, which are 
categorized as hard acids therefore easily bond with hydroxyl groups on the mild steel. For this reason, the value of $X$ indicates the tendency of formation of chemical bond between metal cations in the solution and hydroxyl groups on the mild steel surface. Therefore, HSAB concept is very useful for understanding the incorporation of metal cations in the oxide films [29]. Based on the HSAB concept, hardness of metal cation, $X$ was introduced to explain the corrosion behavior of metals in fresh water [27]. However, $X$ is not suitable corrosion indicator regarding corrosion of metals in fresh water [18]. It is still unknown the possibility of $X$ as an indicator for corrosion of metals in the $10 \mathrm{mM} \mathrm{Cl}^{-}$aqueous solution. The mechanism of corrosion inhibition of metal cations is also unknown. By considering the corrosion rate of mild steel that depends on the metal cations $[18,19], \mathrm{Cl}^{-}$concentration, $\mathrm{pH}[30,31]$ and dissolved oxygen, the present research purpose is to find out the effects of metal cations on corrosion of mild steel, and the mechanism of corrosion inhibition in $10 \mathrm{mM} \mathrm{Cl}^{-}$aqueous solution at an equal level of $\mathrm{pH}$.

In this experiment, comparative conditions were used to study the influence of metal cations on corrosion of mild steel in $10 \mathrm{mM} \mathrm{Cl}^{-}$aqueous solution. The fluctuations of environmental factors were controlled initially to obtain the effective influence of metal cations on corrosion. The influence of metal cations on corrosion of mild steel in the mentioned environment were investigated by electrochemical impedance spectroscopy (EIS), immersion tests, surface observation and analysis with scanning electron microscope (SEM), Energy dispersive X-ray spectroscope (EDS) and X-ray photoelectron spectroscope (XPS).

\section{Experimental}

\subsection{Specimens}

Mild steel sheets $(7 \times 7 \mathrm{~mm}$ in size and $0.7 \mathrm{~mm}$ in thickness $)$ were used as specimens. The chemical composition of the mild steel is shown in the Table 1. The methods used to prepare 
specimens for immersion tests and electrochemical measurements are shown in Fig. 2. To make an electrical contact, a wire was connected with each specimen to perform the electrochemical measurements. All the specimens were molded in epoxy resin (Struers Ltd., EpoFix Resin). The exposed surface of each molded specimen was grounded (Marumoto Struers S5629, LaboForce-3) with SiC abrasive papers from \#400 to \#4000 grit size, then finally polished by colloidal silica. Before the immersion tests, the specimens were taken out from the epoxy resin. All the specimens were ultrasonically cleaned (SIBATA ultrasonic cleaner, SU-2T) in ethanol and then in highly purified water. The specimens were kept in a desiccator to avoid any type of contamination and humidity.

\subsection{Solutions}

Five different salt solutions, $10 \mathrm{mM} \mathrm{NaCl}\left(\mathrm{Na}_{\mathrm{sol}}\right), 0.1 \mathrm{mM} \mathrm{MgCl} 2\left(\mathrm{Mg}_{\mathrm{sol}}\right), 0.1 \mathrm{mM} \mathrm{ZnCl} 2$

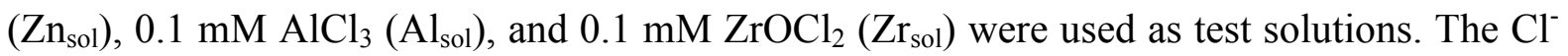
concentration was adjusted to $10 \mathrm{mM}$ by $\mathrm{NaCl}$. In this study, $\mathrm{Na}_{\text {sol }}$ was considered as a standard solution. Water used in this study was highly purified that was distilled two times and then further purified by water purifier (MILIPORE, Simplicity UV). All chemicals used in this study were special analytical grade and obtained from Kanto Chemical Co. Ltd.

Electrochemical reactions are mostly depended on the $\mathrm{pH}$ of the aqueous solution $[30,31]$. The $\mathrm{pH}$ of used solutions was controlled between 5.5 and 6.0 by $0.1 \mathrm{M} \mathrm{NaOH}$ (Table 2). The $\mathrm{pH}$ measurement of the solutions before and after immersion tests were carried out using the pH meter (Eutech Instruments Pte. Ltd., Cyber-Scan 6000).

\subsection{Immersion tests}

Specimens were immersed in the solutions for $259.2 \mathrm{ks}(3 \mathrm{~d})$ at $25^{\circ} \mathrm{C}$. The test performing bottles were open to the air during immersion tests. The mass of the specimens was measured using a micro-balance (METTLER TOLEDO MX5, Pro FACT) before and after immersion tests, and the corrosion rates were calculated from the mass variation using the equation (7). 


$$
\text { Corrosion rate }(\mu \mathrm{m} / \mathrm{y})=\frac{\left(\mathrm{M}_{1}-\mathrm{M}_{2}\right)}{\mathrm{D} \times \mathrm{S} \times \mathrm{t}} \times 3650
$$

Where $M_{1}$ is mass before immersion (mg), $M_{2}$ is mass after immersion (mg), $D$ is density of specimen $\left(\mathrm{g} / \mathrm{cm}^{3}\right), \mathrm{S}$ is surface area of specimen $\left(\mathrm{cm}^{2}\right)$ and $\mathrm{t}$ is immersion time (d).

\subsection{Electrochemical tests}

All the electrochemical measurements were carried out in a three-electrode system using a potentiostat (Pocketstat, IVIUM TECHNOLOGIES). Open-circuit potential (OCP) was measured for $1 \mathrm{~h}$ at $25^{\circ} \mathrm{C}$ and the potentiodynamic measurements were carried out in the cathodic and anodic direction with a scan rate of $1 \mathrm{mV} / \mathrm{s}$. The cathodic and anodic scan was started separately to obtain the individual electrochemical properties of mild steel immersed in the corresponding solutions with metal cation. A platinum plate of $4 \mathrm{~cm}^{2}$ and an $\mathrm{Ag} / \mathrm{AgCl}$ electrode (SSE) immersed in a saturated $\mathrm{KCl}$ solution were used as counter and reference electrodes, respectively. The exposed surface area of working electrode in the solution was 49 $\mathrm{mm}^{2}$. EIS measurements were carried out in the frequency range from $10 \mathrm{kHz}$ to $1 \mathrm{mHz}$, and a modulation amplitude of $10 \mathrm{mV}$. Reproducible data were acquired in all electrochemical measurements.

\subsection{Surface observations and analysis}

Surface morphology is the important criteria which reflects the corrosion behavior of the mild steel regarding the solution. Surface observation of specimen after immersion were carried out to clarify the variance of the specified corrosion behavior of mild steel in the different solutions of metal cation. Before and after the immersion tests, the surfaces of the specimens were observed by a digital camera (Nikon D80-DSLR), optical microscope (WRAYMER-G500) and Scanning Electron Microscope (SEM) using secondary electrons imaging (SEM, JEOL Ltd., JSL6510-LA). For SEM observation, the acceleration voltage of the electron beam was set at $10 \mathrm{kV}$ in order to be sensitive to the morphology of the surface. EDS analysis was carried out to analyze the surface composition of the specimen after 
immersion tests.

Surface analysis was carried out to clarify the situation of specimen surface after immersion in the solutions with different metal cation. The center area of the specimens after immersion was analyzed by X-ray Photoelectron Spectroscope (XPS, JEOL Ltd., JPS-9200) using a monochrome $\mathrm{Al} \mathrm{K} \alpha \mathrm{X}$-ray source. Before the analysis, the immersed specimens were cleaned ultrasonically by ethanol and then in highly purified water. After cleaned, specimens were kept in a desiccator to avoid humidity and any type of contamination. The diameter of specimen analyzed by the XPS was $3 \mathrm{~mm}$.

\section{Results}

\subsection{Immersion tests}

Fig. 3 (a) shows the appearance of specimens at the starting of immersion and 3 (b) shows the specimens after immersion in $\mathrm{Na}_{\text {sol }}, \mathrm{Mg}_{\text {sol }}, \mathrm{Zn}_{\text {sol }}, \mathrm{Al}_{\text {sol }}$ and $\mathrm{Zr}_{\text {sol }}$ during $259.2 \mathrm{ks}(3 \mathrm{~d})$ at $25^{\circ} \mathrm{C}$. In Fig. 3 (b), there are many brown color corrosion products are observed on the specimen surface in the case of $\mathrm{Na}_{\text {sol }}$, and $\mathrm{Mg}_{\text {sol. }}$. The amounts of corrosion products in $\mathrm{Zn}_{\text {sol }}$, $\mathrm{Al}_{\text {sol }}$, and $\mathrm{Zr}_{\text {sol }}$ are decreased compared with $\mathrm{Na}_{\text {sol }}$ and $\mathrm{Mg}_{\text {sol }}$. Fig. 3 (c) shows the surface images of specimens after immersion in the solutions before (upper row) and after (bottom row) ultrasonic cleaning. Brown color corrosion products were deposited on the specimen surface that were observed before ultrasonic cleaning, and the amount was varied depending on the solutions. Less amount of brown color corrosion products is observed in the case of $\mathrm{Zn}_{\text {sol }}$ as compared to the other solutions. The corrosion rates were calculated from the mass loss after immersion for $259.2 \mathrm{ks}(3 \mathrm{~d})$ in the different solutions. The density of specimen, $7.874 \mathrm{~g} / \mathrm{cm}^{3}$ was used to calculate the corrosion rates [32]. Fig. 4 shows the corrosion rate as a function of $X$. The corrosion rate is gradually decreased with increasing the value of $X$ up to 5, and over 5, the corrosion rate is not decreased gradually. The correlation coefficient is -0.42 indicating that 
corrosion rate is not clearly related with $X$. However, the results of immersion corrosion tests indicate that $\mathrm{Zn}_{\text {sol }}$ has the better corrosion inhibition effect on mild steel in high concentration of $\mathrm{Cl}^{-}$containing aqueous solution.

The $\mathrm{pH}$ of the test solutions before and after immersion for $259.2 \mathrm{ks}$ (3d) are shown in Table 2. Initial $\mathrm{pH}\left(\mathrm{pH}_{\text {int }}\right)$ of $\mathrm{Al}_{\text {sol }}$ and $\mathrm{Zr}_{\text {sol }}$ showed low value than other solutions of metal cation and it were adjusted $\left(\mathrm{pH}_{\mathrm{adj}}\right)$ to 5.7 and 5.8. Average $\mathrm{pH}$ of the test solutions is around 5.8. The $\mathrm{pH}$ was slightly increased after immersion $\left(\mathrm{pH}_{\text {corr }}\right)$ in all solutions of metal cations for $259.2 \mathrm{ks}$ due to the formation of $\mathrm{OH}^{-}$at the metal surface $[18,33]$.

\subsection{Electrochemical tests}

\subsubsection{Open-circuit potential (OCP) and potentiodynamic polarization}

The open circuit potentials of mild steel measured in the solution of metal cations rapidly reach a stable value after around $3000 \mathrm{~s}$ of immersion (Fig. 5 (a)). All the measured values are confined in a reduced range of potentials between $-0.22 \mathrm{~V}$ and $-0.45 \mathrm{~V}$. Only slight difference can be noticed in the case of $\mathrm{Mg}_{\text {sol }}, \mathrm{Zn}_{\text {sol }}, \mathrm{Al}_{\text {sol }}$ and $\mathrm{Zr}_{\text {sol }}$ as compared to $\mathrm{Na}_{\text {sol }}$, and $\mathrm{Na}_{\text {sol }}$ induces the most negative open-circuit potential and $\mathrm{Zn}_{\text {sol }}$ the most positive one. Open-circuit potentials at $1 \mathrm{~s}$ and at $3000 \mathrm{~s}$ as a function of $X$ are shown in Fig. 5 (b). The metal cations which have large $X$ show no significant difference. However, $\mathrm{Zn}_{\text {sol }}$ shows higher average potential than $\mathrm{Na}_{\mathrm{sol}}$, and $\mathrm{Na}_{\mathrm{sol}}$ shows the lowest average potential at $3000 \mathrm{~s}$ as compared to the other solutions with metal cations.

Fig. 6 (a) shows the cathodic polarization curves and Fig. 6 (b) shows the anodic polarization curves. From the Figs. 6 (a) and (b) (indicated by arrow), it is found that $\mathrm{Zn}_{\text {sol }}$ shows lower current density as compared to the $\mathrm{Na}_{\text {sol }}$ and $\mathrm{Na}_{\text {sol }}$ shows the highest current density among used solutions both in cathodic and anodic polarization curves. For the other solutions of metal cation, there is no significant influences of cathodic and anodic reactions as well. 


\subsubsection{Electrochemical Impedance Spectroscopy (EIS)}

EIS measurements were carried out to elucidate the initial corrosion behavior of the mild steel and the effect of metal cations on the properties of the protective layer. Fig. 7 shows the Bode diagram of (a) Impedance plots, (b) phase shift plots and (c) Nyquist plots of the mild steel in the solutions after immersion for $1 \mathrm{~h}$, and impedance spectra depend on the kinds of metal cations. There was no rust formed during EIS measurements. The fitted lines calculated by Randle's equivalent circuit model [34-36] are also shown in Fig. 7, and the equivalent circuit model is shown in Fig. 7 (d). All the spectra can be well described by equivalent circuit. This model consists of solution resistance $\left(\mathrm{R}_{\mathrm{sol}}\right)$, charge-transfer resistance $\left(\mathrm{R}_{\mathrm{ct}}\right)$, and constant phase element (CPE), Q. The impedance can be expressed in terms of $R_{\text {sol }}, R_{c t}$ and CPE parameters $\mathrm{n}$ and $\mathrm{Q}$ by equation (8) [37-40].

$$
Z=\mathrm{R}_{\mathrm{sol}}+\frac{\mathrm{R}_{\mathrm{ct}}}{1+(j \omega)^{n} \mathrm{QR}_{\mathrm{ct}}}
$$

Where $\omega=2 \pi f$ and $f$ is the frequency in units of $\mathrm{Hz}$. The value of CPE parameter, $\mathrm{n}$ varies from 0 to 1 . When $n=1$, the CPE behaves as a pure capacitor, and when $n=0$, the CPE behaves as a pure resistor. The CPE parameters are calculated by using the equation (8). The simulated values of CPE parameters are shown in the table 3.

The magnitude of impedance at low frequencies in Bode diagram implies the corrosion resistance of mild steel in the solution. Among five experimental solutions, $\mathrm{Zn}_{\text {sol }}$ shows the larger impedance at low frequency (Fig. 7 (a)). Higher phase shift is observed for $\mathrm{Zn}_{\text {sol }}$ (Fig. 7 (b)), and magnitude of each Nyquist plots are different depending on the solutions (Fig. 7 (c)). Larger magnitude of Nyquist plot is observed in the case of $\mathrm{Zn}_{\text {sol }}$ among other solutions.

The (a) $\mathrm{R}_{\text {sol }}$, (b) $\mathrm{R}_{\text {ct }}$, and (c) $\mathrm{Q}$ as a function of $X$ are shown in Fig. 8. The $\mathrm{R}_{\text {sol }}$ are not significantly changed with $X$ (Fig. 8 (a)). Higher $\mathrm{R}_{\text {ct }}$ is observed in the case of $\mathrm{Zn}_{\text {sol }}$ (Fig. 8 (b)) than other solutions, and there are no significant influences for the other solutions. High $\mathrm{R}_{\mathrm{ct}}$ means that the mild steel has high corrosion resistance in the solution. This is supposed that 
$\mathrm{Zn}_{\text {sol }}$ exposes the high corrosion resistance $\left(\mathrm{R}_{\mathrm{ct}}\right)$ than other solutions. The value of $\mathrm{Q}$ is decreasing with increasing the value of $X$ up to 5 and then the $\mathrm{Q}$ is again increasing with increasing the value of $X$ (Fig. 8 (c)). $\mathrm{Zn}_{\text {sol }}$ shows the lowest value of $\mathrm{Q}$ than other solutions of metal cation (Table 3). Q represents the structure of solution/metal interface and the area of defects in the protective film on the surface [19, 22]. Otani et. al [19] reported that the decrease in $\mathrm{Q}$ indicates that $\mathrm{Zn}^{2+}$ can decrease the defect in the protective film on the mild steel. Therefore, this result indicates that $\mathrm{Zn}_{\text {sol }}$ has relatively perfect oxide film and narrow metal/solution interface area than other solutions.

The results of EIS and immersion tests showed that the corrosion rate of the mild steel decreases with increasing the value of $X$ up to 5. In addition, the correlation coefficients of $\mathrm{R}_{\text {sol }}$ vs $X, \mathrm{R}_{\text {ct }}$ vs $X$, and $\mathrm{Q}$ vs $X$ are $0.51,0.15$ and -0.01 respectively (Fig. 8 (a), (b) and (c)), and these values are too small to regard corrosion rate with hardness of metal cations, $X$. Therefore, the hardness of metal cations, $X$, is not suitable as a corrosion indicator of mild steel in $10 \mathrm{mM}$ $\mathrm{Cl}^{-}$aqueous solution. The results obtained from EIS and immersion tests, suggest that $\mathrm{Zn}_{\text {sol }}$ has the high corrosion resistance over other metal cations used in this study in $10 \mathrm{mM} \mathrm{Cl}^{-}$aqueous solution.

\subsection{Surface observations and analysis}

The results of immersion corrosion tests showed that the corrosion rates of the specimens after immersion for $259.2 \mathrm{ks}(3 \mathrm{~d})$ is different in each solution. The changes in the appearance of specimen surfaces were observed to clarify the situation. Specimen surface was first observed by optical microscope, and grain boundaries were observed. To be more clear about surface changes, observations were carried out by SEM. Fig. 9 shows the surface SEM images of specimen and quite different surface morphologies are observed for the different solutions. SEM images depict the clear grain boundaries that is observed in the case of $\mathrm{Na}_{\text {sol }}, \mathrm{Mg}_{\text {sol }}, \mathrm{Al}_{\text {sol }}$ and $\mathrm{Zr}_{\text {sol }}$. Pits and grain boundaries is observed in the case of $\mathrm{Na}_{\text {sol }}$. A few numbers of pits are 
also observed for $\mathrm{Mg}_{\text {sol }}, \mathrm{Al}_{\text {sol }}$ and $\mathrm{Zr}_{\text {sol }}$, and some corrosion products are deposited on the surface in the case of $\mathrm{Zn}_{\text {sol }}$. $\mathrm{Zn}^{2+}$ may form less soluble salts and tend to precipitate in a form of hydroxide, oxide, or hydroxy salts. Severe corrosion is observed for $\mathrm{Na}_{\text {sol }}$ as compared to the other solutions. The results suggest that corrosion may affected with corrosion inhibiting effect of the metal cation and $\mathrm{Zn}^{2+}$ has the better corrosion inhibition effect on mild steel in the $10 \mathrm{mM} \mathrm{Cl}^{-}$aqueous solution. An EDS analysis result is shown in Fig. 10. Left side of Fig. 10 shows the SEM image of EDS analysis area, and right side shows the EDS analysis result, and $\mathrm{Zn}$ is found on the mild steel surface after immersion in the solution.

The results of the immersion corrosion tests and electrochemical measurements suggest that the protectiveness of passive film may be affected by the metal cations in the solution. For better understanding the influence of metal cations and also the incorporation of metal cations on the surface film structure, the specimen surfaces after the immersion tests were investigated by XPS. Fig. 11 shows the XPS wide spectra of mild steel surface after immersion in the solution with metal cations. This figure clearly shows the peak of Zn2p1/2 and Zn2p3/2 after immersion in the $\mathrm{Zn}_{\text {sol. }}$ Fig. 12 (a) shows the XPS narrow spectra of $\mathrm{Na} 1 \mathrm{~s}$ and Fig. 12 (b) shows the $\mathrm{Mg} 1 \mathrm{~s}, \mathrm{Zn} \mathrm{2p3/2,} \mathrm{Al} \mathrm{2p3/2} \mathrm{and} \mathrm{Zr} \mathrm{3d5/2} \mathrm{spectra} \mathrm{in} \mathrm{each} \mathrm{solution.} \mathrm{XPS} \mathrm{analysis}$ results show that there is no peak of $\mathrm{Na} 1 \mathrm{~s}$ on the specimen after immersion in all solution suggesting that $\mathrm{Na}^{+}$cannot form any compound on the mild steel in the solution (Fig. 12 (a)). Clear peak is observed (Fig 12 (b)) in the case of $\mathrm{Zn}^{2+}$ among all experimental metal cations meaning that only $\mathrm{Zn}^{2+}$ remains on the mild steel after immersion in the solution. $\mathrm{Zn}^{2+}$ may precipitates as oxides or hydroxides $[18,19]$ and make a chemical bond with the oxide film of mild steel in $10 \mathrm{mM} \mathrm{Cl}^{-}$aqueous solution and forms a metal cation layer which inhibits the anodic and cathodic reactions, and protects the dissolution of metal [18, 19]. These results correspond with other tests like as immersion tests and electrochemical tests. 


\section{Discussions}

According to the results in this study, the corrosion properties of mild steel significantly affected by metal cations in the solution. Electrochemical measurements showed that the decrease of corrosion rate of mild steel due to an inhibitory effect of both the anodic reaction of iron oxidation and the cathodic reaction of oxygen reduction. This inhibitory effect might be the consequences of metal cation that was incorporated on the oxide films of the metal surface and suppress the corrosion rate.

The structure of passive films formed on mild steels in neutral solution has been reported by many researchers by electron diffraction, and the passive films consist of $\mathrm{Fe}_{3} \mathrm{O}_{4}$ and $\gamma-\mathrm{Fe}_{2} \mathrm{O}_{3}$ in neutral solutions [41-44]. The possible corrosion mechanism of metal cations with the passive film of mild steel in the $10 \mathrm{mM} \mathrm{Cl}^{-}$aqueous solution is shown in Fig. 13. Metal cations $\left(\mathrm{M}^{\mathrm{n}+}=\right.$ $\mathrm{Na}^{+}, \mathrm{Mg}^{2+}, \mathrm{Al}^{3+}$, and $\mathrm{Zr}^{4+}$ ) are not able to make (Fig.13 (a)) any compound (precipitate) or unable to make any bond with the oxide film of mild steel (Fig.13 (b)). From the Pourbaix diagram, it is known that $\mathrm{Mg}^{2+}\left(\left[\mathrm{Mg}^{2+}=0.1 \mathrm{mM}\right]\right)$ and $\mathrm{Zr}^{4+}\left(\left[\mathrm{Zr}^{4+}=0.1 \mathrm{mM}\right]\right)$ cannot precipitate as oxides or hydroxides at $\mathrm{pH}$ lower than 8 [45]. After immersion, the $\mathrm{pH}$ of the solution was about 6.5 (Table 2). Therefore, $\mathrm{Mg}^{2+}$ and $\mathrm{Zr}^{4+}$ are not able to precipitate on the mild steel in this $\mathrm{pH} . \mathrm{Al}^{3+}\left(\left[\mathrm{Al}^{3+}=0.1 \mathrm{mM}\right]\right)$ is able to form oxides or hydroxides on mild steel at $\mathrm{pH}$ lower than 6 [45]. However, the oxides or hydroxides are not stable $[45,46]$. Then $\mathrm{Cl}^{-}$can arrive on the metal surface through destroying the oxide films and initiate the electrochemical reactions. Consequently, $\mathrm{Al}_{\text {sol }}$ shows higher corrosion rate than $\mathrm{Zn}_{\text {sol }}$ (Fig. 4) in this experiment due to the instability of the oxides or hydroxides that are formed on mild steel $[45,46]$.

The possible corrosion mechanism of $\mathrm{Zn}^{2+}$ would be different from other metal cations $\left(\mathrm{M}^{\mathrm{n}+}=\mathrm{Na}^{+}, \mathrm{Mg}^{2+}, \mathrm{Al}^{3+}\right.$, and $\left.\mathrm{Zr}^{4+}\right)$. EDS and XPS analysis results show the clear evidence that $\mathrm{Zn}^{2+}$ remains on the mild steel after immersion in the solution among metal cations used in this study. It is expected that $\mathrm{Zn}^{2+}$ reacts with the $\mathrm{OH}^{-}$(reaction (5)) to form hydroxides (reaction 
(9)) in the cathodic area due to locally high $\mathrm{pH}$ near the surface $[33,45,47]$. From the Pourbaix diagram, it is also known that $\mathrm{Zn}^{2+}\left(\left[\mathrm{Zn}^{2+}=0.1 \mathrm{mM}\right]\right)$ can precipitate as hydroxides on the mild steel at $\mathrm{pH}$ around 6 [45].

$$
\mathrm{Zn}^{2+}+2 \mathrm{OH}^{-} \rightarrow \mathrm{Zn}(\mathrm{OH})_{2}
$$

The mechanism of corrosion inhibition is as follows:

The produced hydroxides can possibly bind in a chemical bond with the outermost layer of the oxide film of mild steel $[45,48]$. Another possibility is that $\mathrm{Zn}^{2+}$ directly makes a bond with $\mathrm{OH}^{-}$of oxide film (oxide film contains so many $\mathrm{OH}^{-}$) and thus form a metal cation layer on the oxide film (Fig. 13 (c)) [18, 19]. Several studies also have shown that metal cations that have large $X$ can easily bond with $\mathrm{OH}^{-}$on the oxide film of mild steel $[18,19,28,29]$. The anodic area may be smaller than the cathodic area and the zinc layer may also cover the anodic area. Therefore, the metal cation layer of $\mathrm{Zn}^{2+}$ would have good protective ability against the $\mathrm{Cl}^{-}$ attack in the solution, and the protective layer would prevent the cathodic and anodic reactions (Fig. $13(d))$ on the mild steel $[18,19]$. For this reason, the corrosion rate of the mild steel immersed in $\mathrm{Zn}_{\text {sol }}$ was lower than those in other solutions with metal cations.

\section{Conclusion}

The effects of metal cations on mild steel corrosion in $10 \mathrm{mM} \mathrm{Cl}^{-}$aqueous solution were investigated by SEM, EDS, XPS, and EIS.

1. The corrosion behavior of mild steel in the $10 \mathrm{mM} \mathrm{Cl}$ - aqueous solution was changed with $X$, while corrosion rate was not highly correlated with $X$.

2. Different surface morphologies were observed by SEM, and it was found that some corrosion products were deposited on the surface after immersion in the $\mathrm{Zn}_{\text {sol }}$.

3. Among the metal cations used in this study, only $\mathrm{Zn}^{2+}$ was detected by XPS on the specimen surface after immersion in the $\mathrm{Zn}_{\text {sol }}$. 
4. $\mathrm{Zn}^{2+}$ forms a protective layer with the oxide film of mild steel in the solution, and thus inhibits the electrochemical reactions, and consequently lowers the corrosion rate as well.

\section{Acknowledgements}

This study was supported by the Salt Science Research Foundation, No. 1609, XPS analysis was conducted at the Laboratory of XPS analysis, Hokkaido University, supported by 'Nanotechnology Platform' Program of the Ministry of Education, Culture, Sports, Science and Technology (MEXT), Japan, and the SEM-EDS observation of this study was conducted at the Laboratory of XPS analysis, Hokkaido University, supported by 'Material Analysis and Structure Analysis Open Unit (MASAOU)'. 


\section{References}

[1] R. E. Melchers, Modelling immersion corrosion of structural steels in natural fresh and brackish waters, Corros. Sci., 48 (2006) 4174-4201.

[2] G. S. Vasyliev, The influence of flow rate on corrosion of mild steel in hot tap water, Corros. Sci., 98 (2015) 33-39.

[3] C. P. Gardiner and R. E. Melchers, Corrosion of mild steel by coal and iron ore, Corros. Sci., 44 (2002) 2665-2673.

[4] R. T. Foley, Role of the chloride ion in iron corrosion, Corrosion, 26 (1970) 58-70.

[5] H. Fang, B. Brown and S. Nesic, Effects of sodium chloride concentration on mild steel corrosion in slightly sour environments, Corrosion, 67 (2011) 1-12.

[6] T. Haruna, K. Domoto and T. Shibata, Effect of sulfate ion on corrosion of carbon steel in carbonate/bicarbonate solutions, Japan Society of Corrosion Engineering, 51 (2002) 350355.

[7] G. C. White, Current chlorination and dechlorination practices in the treatment of potable water, wastewater and cooling water. In: Jolley RL, ed. Water chlorination: environmental impact and health effects. Ann Arbor, MI, Ann Arbor Sci., 1 (1978) 1-18.

[8] G. R. Dychdala, Chlorine and chlorine compounds. In: Black SS, ed. Disinfection, sterilization and preservation, second edition. Philadelphia, PA, Lea and Febiger, (1977) 167-195.

[9] Guidelines for drinking water quality, second edition. Health criteria and other supporting information. World Health Organization, Geneva (1996).

[10] H. J. Engell and N. D. Stolica, Untersuchungen über lochfraß an passiven elektroden aus unlegiertem Stahl in chlorionenhaltiger schwefelsäure, Arch. Eisenhuttenw, 30 (1959) 239-248. 
[11] L. A. Krebs, J. Kruger, M. B. Ives, J. L. Luo, and J. R. Rodda, Passivity of metals and semiconductors, The Electrochemical Society, Pennington, NJ (2001) 561-562.

[12] D. D. Macdonald, The point defect model for the passive state, J. Electrochem. Soc., 139, (1992) 3434-3449.

[13] E. McCafferty, Introduction to corrosion science, Springer (2010) 283-286.

[14] H. J. Engell, Stability and breakdown phenomena of passivating films, Electrochim. Acta, 22 (1977) 987-993.

[15] K. G. Weil and D. Menzel, Die einwirkung von halogenionen auf passives eisen, Z. Electrochem. Soc., 63 (1959) 669-673.

[16] S. Miyake, Study on the corrosion of iron by electron diffraction, Sci. Papers Inst. Phys. Chem. Res., 36 (1939) 363-370.

[17] E. McCafferty, Sequence of steps in the pitting of aluminum by chloride ions, Corros. Sci., 45 (2003) 1421-1438.

[18] K. Otani, M. Sakairi, Effects of metal cations on corrosion of mild steel in model fresh water, Corros. Sci., 111 (2016) 302-312.

[19] K. Otani, M. S. Islam and M. Sakairi, Inhibition ability of gluconates for fresh water corrosion of mild steel enhanced by metal cations, J. Electrochem. Soci., 164 (2017) C498C504.

[20] M. Kato, Inhibitive effect of aluminium ion for iron corrosion in water (Japanese), Boshoku Gijutsu, 31 (1982) 27-33.

[21] S. Takasaki, Development of environmentally acceptable technology for cooling water treatment, Zairyo-to-Kankyo, 64 (2015) 114-120.

[22] M. Mahdavian and R. Naderi, Corrosion inhibition of mild steel in sodium chloride solution by some zinc complexes, Corros. Sci., 53 (2011) 1194-1200. 
[23] R. A. Prabhu, T. V. Venkatesha and B. M. Praveen, Electrochemical study of the corrosion behavior of zinc surface treated with a new organic chelating inhibitor, International scholarly research network, ISRN Metallurgy, (2012) 1-7.

[24] J. Xu, L. Jiang, W. Wang, L. Tang and L. Cui, Effectiveness of inhibitors in increasing chloride threshold value for steel corrosion, Water Sci. and Eng., 6 (2013) 354-363.

[25] G. N. Lewis, Valence and the structure of atoms and molecules, The Chemical Catalog Co., New York (1923).

[26] R. G. Pearson, Hard and soft acids and bases, J. Am. Chem. Soc., 85 (1963) 3533-3539.

[27] K. Otani, M. Sakairi, R. Sasaki, A. Kaneko, Y. Seki, Effect of metal cations on corrosion behavior and surface film structure of the A3003 aluminum alloy in model tap waters, J. Solid State Electrochem., 18 (2014) 325-332.

[28] M. Misono, E. Ochiai, Y. Saito, Y. Yoneda, A new dual parameter scale for the strength of lewis acids and bases with the evaluation of their softness, J. Inorg. Nucl. Chem., 29 (1967) 2658-2691.

[29] S. Zhang, T. Shibata, T. Haruna, Inhibition of metal cations to intergranular stress corrosion cracking of sensitized Type 304 stainless steel, Corros. Sci., 47 (2005) 10491061.

[30] K. F. Ankinpelumi, Investigation the effect of $\mathrm{pH}$ level on corrosion rate, University of Lagos, Lagos (2012).

[31] I. A. Ammar and S. Riad, Effect of pH on corrosion potentials, J. Phys. Chem., 62 (1958) $150-154$.

[32] The chemical society of Japan, Handbook of chemistry basic, edition 2, Maruzen, Tokyo, 2004 (Japanese). 
[33] J. Han, B. N. Brown, D. Young and S. Nesic, Mesh-capped probe design for direct pH measurements at an activity corroding metal surface, J. Appl. Electrochem., 40 (2010) 683-690.

[34] I. Martinez, C. Andrade, Application of EIS to cathodically protected steel: tests in sodium chloride solution and in chloride contaminated concrete, Corros. Sci., 50 (2008) 29482958.

[35] A. Popova, M. Christov, A. Vasilev, Inhibitive properties of quaternary ammonium bromides of N-containing heterocycles on acid mild steel corrosion. Part II: EIS results, Corros. Sci., 49 (2007) 3290-3302.

[36] D. A. Lopez, S.N. Simison and S.R. de Sanchez, Inhibitors performance in $\mathrm{CO}_{2}$ corrosion EIS studies on the interaction between their molecular structure and steel microstructure, Corros. Sci., 47 (2005) 735-755.

[37] B. Hirschorn, M. E. Orazem, B. Tribollet, V. Vivier, I. Frateur and M. Musiani, Determination of effective capacitance and film thickness from constant-phase-element parameters, Electrochim. Acta, 55 (2010) 6218-6227.

[38] M. E. Orazem, I. Frateur, B. Tribollet, V. Vivier, S. Marcelin, Dielectric properties of materials showing constant-phase-element (CPE) impedance response. J. Electrochem. Soci., 160 (2013) C215-C225.

[39] P. C. Torres, T. J. Mesquita and R. P. Nogueira, Relationship between the origin of constant-phase element behavior in electrochemical impedance spectroscopy and electrode surface structure, J. Phys. Chem. 119 (2015) 4136-4147.

[40] G. J. Brug, A. L. G. Van Den Eeden, M. S. Rehbach and J. H. Sluyters, The analysis of electrode impedances complicated by the presence of a constant phase element, J. Electroanal Chem., 176 (1984) 275-295. 
[41] I. Iitaka, S. Miyake, T. Iimori, Examination of passive iron by electron diffraction, Nature, 139 (1937) 156.

[42] M. Cohen, An electron diffraction study of films formed by sodium nitrite solution on iron, J. Phys. Chem., 56 (1952) 451-453.

[43] E. McCafferty and J. P. Wightman, Determination of the concentration of surface hydroxyl groups on metal oxide films by a quantitative XPS method, Surf. Inter. Anal., 26 (1998) 549-564.

[44] A. Valeria and M. A. Christopher Brett, Characterization of passive films formed on mild steels in bicarbonate solution by EIS, Electrochim. Acta, 47 (2002) 2081-2091.

[45] M. Pourbaix, Atlas of electrochemical equilibria in aqueous solutions, National Association of Corrosion Engineers, Huston, Texas (1974).

[46] A. Y. Chatalov, Effect du pH sur le comportement electrochimique des metaux et leur resistance a la corrosion, Dokl. Akad. Naouk S. S. S. R., 86 (1952) 7-775.

[47] E. Tada and H. Kaneko, Galvanic corrosion of a $\mathrm{Zn} /$ steel couple in aqueous $\mathrm{NaCl}$, ISIJ Int., 51 (2011) 1882-1889.

[48] O. T. De Rincon, O. Perez, E. Paredes, Y. Caldera, C. Urdaneta and I. Sandoval, Longterm performance of $\mathrm{ZnO}$ as a rebar corrosion inhibitor, Cement and Concrete Composites, 24 (2002) 79-87. 
Tables and Figures

Table 1 Chemical composition of specimen (mass \%)

\begin{tabular}{cccccc}
\hline $\mathrm{C}$ & $\mathrm{Si}$ & $\mathrm{Mn}$ & $\mathrm{P}$ & $\mathrm{S}$ & $\mathrm{Fe}$ \\
\hline 0.020 & 0.010 & 0.180 & 0.015 & $<0.01$ & Bal. \\
\hline
\end{tabular}


Table $2 \mathrm{pH}$ of the solution used for immersion tests, initial value $\left(\mathrm{pH}_{\mathrm{int}}\right)$, after adjust $\left(\mathrm{pH}_{\mathrm{adj}}\right)$ and after immersion of specimens $\left(\mathrm{pH}_{\mathrm{corr}}\right)$.

\begin{tabular}{cccc}
\hline Test solutions & $\mathrm{pH}_{\text {int }}$ & $\mathrm{pH}_{\text {adj }}$ & $\mathrm{pH}_{\text {corr }}$ \\
\hline $\mathrm{Na}_{\text {sol }}$ & 5.8 & 5.8 & 6.3 \\
$\mathrm{Mg}_{\text {sol }}$ & 5.8 & 5.8 & 6.5 \\
$\mathrm{Zn}_{\text {sol }}$ & 5.8 & 5.8 & 6.5 \\
$\mathrm{Al}_{\text {sol }}$ & 4.2 & 5.7 & 6.5 \\
$\mathrm{Zr}_{\text {sol }}$ & 3.8 & 5.8 & 6.5 \\
\hline
\end{tabular}


Table 3 The simulated values of CPE parameters of mild steel after immersion in the solutions for $1 \mathrm{~h}$.

\begin{tabular}{ccccc}
\hline Solutions & $\begin{array}{c}\mathrm{R}_{\text {sol }} \\
\left(\mathrm{k} \Omega \mathrm{cm}^{2}\right)\end{array}$ & $\begin{array}{c}\mathrm{R}_{\mathrm{ct}} \\
\left(\mathrm{k} \Omega \mathrm{cm}^{2}\right)\end{array}$ & $\begin{array}{c}\mathrm{Q} \\
\left(\mu \mathrm{s}^{\mathrm{n}} \Omega^{-1} \mathrm{~cm}^{-2}\right)\end{array}$ & $\mathrm{n}$ \\
\hline $\mathrm{Na}_{\text {sol }}$ & 0.45 & 5.83 & 10.0 & 0.77 \\
$\mathrm{Mg}_{\text {sol }}$ & 0.43 & 8.81 & 4.93 & 0.77 \\
$\mathrm{Zn}_{\text {sol }}$ & 0.43 & 25.0 & 2.04 & 0.74 \\
$\mathrm{Al}_{\text {sol }}$ & 0.44 & 9.88 & 6.60 & 0.83 \\
$\mathrm{Zr}_{\text {sol }}$ & 0.46 & 11.73 & 8.20 & 0.82 \\
\hline
\end{tabular}


(a)

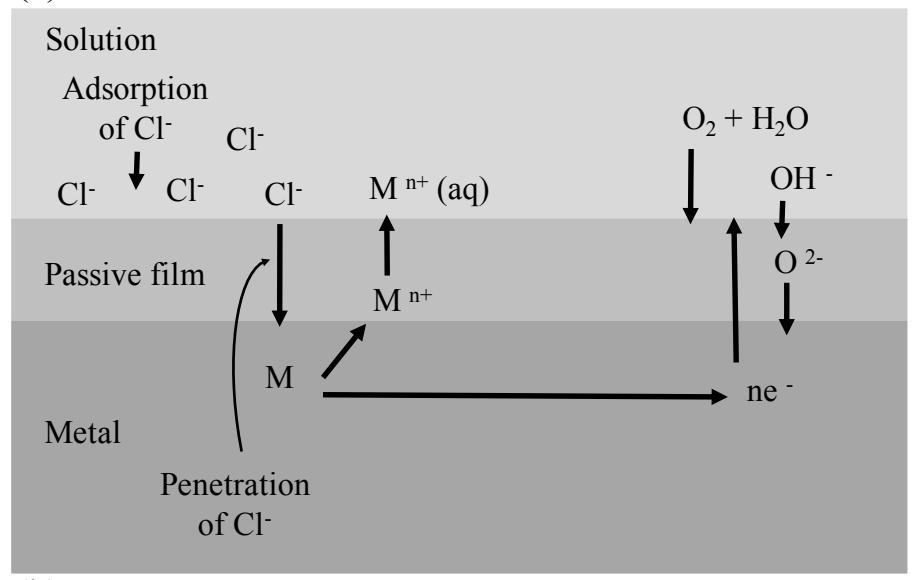

(b)

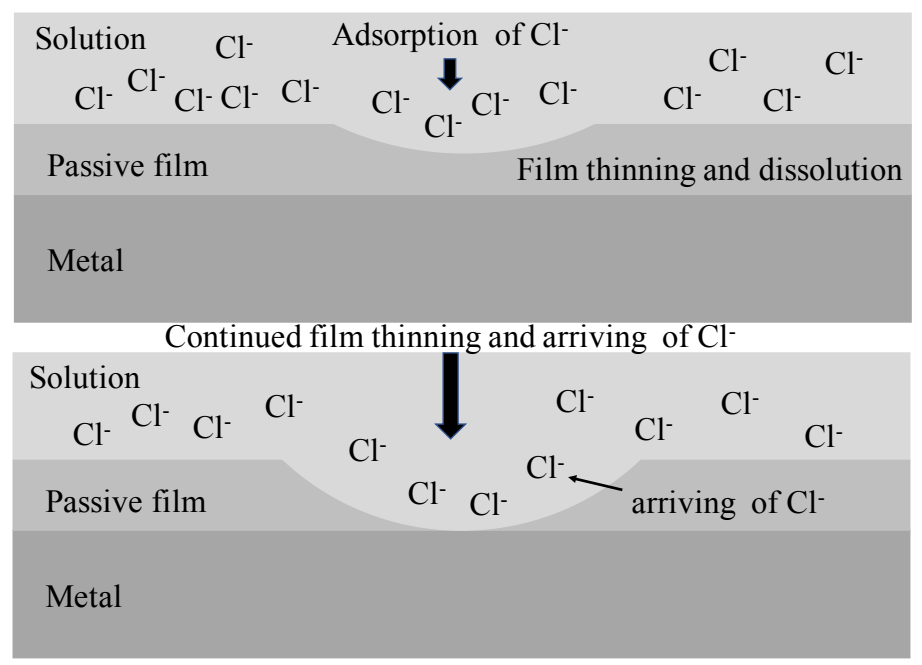

(c)

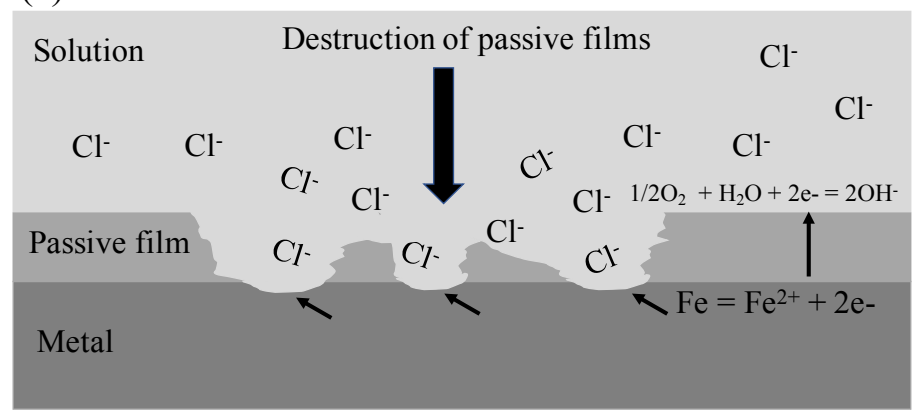

Fig. 1 Schematic representation of adsorption of $\mathrm{Cl}^{-}$on the metal surface by (a) penetration, (b) film thinning, and (c) dissolution with electrochemical reactions on mild steel surface in 10 $\mathrm{mM} \mathrm{Cl}^{-}$aqueous solution. 
Specimen preparation for immersion tests

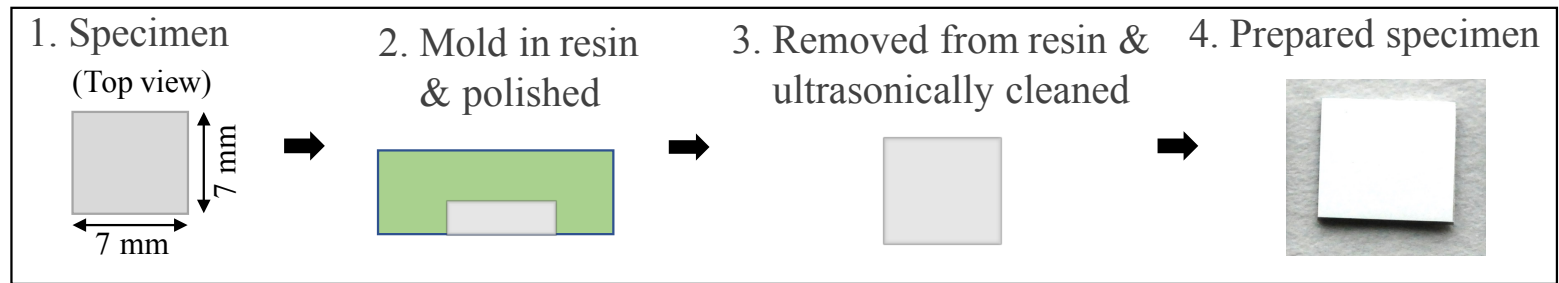

Specimen preparation for electrochemical tests

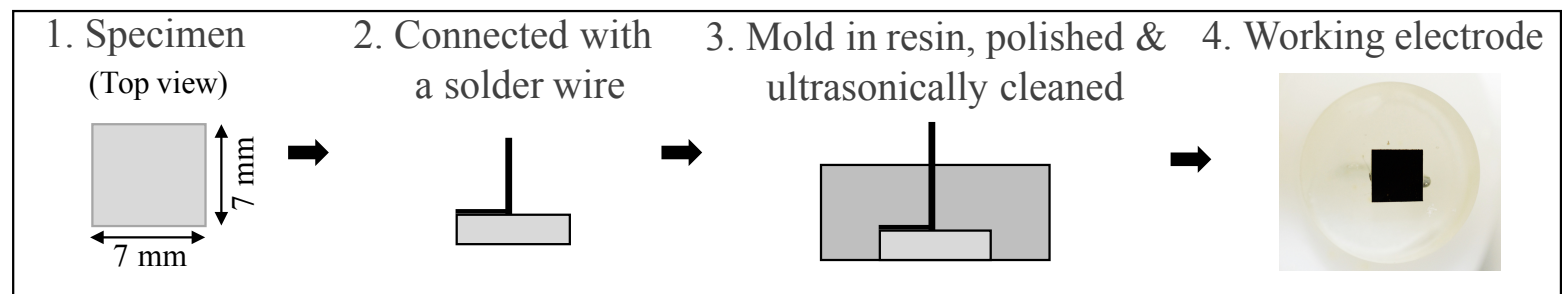

Fig. 2 Schematic images of methods used to prepare the specimens for immersion tests and electrochemical tests. 


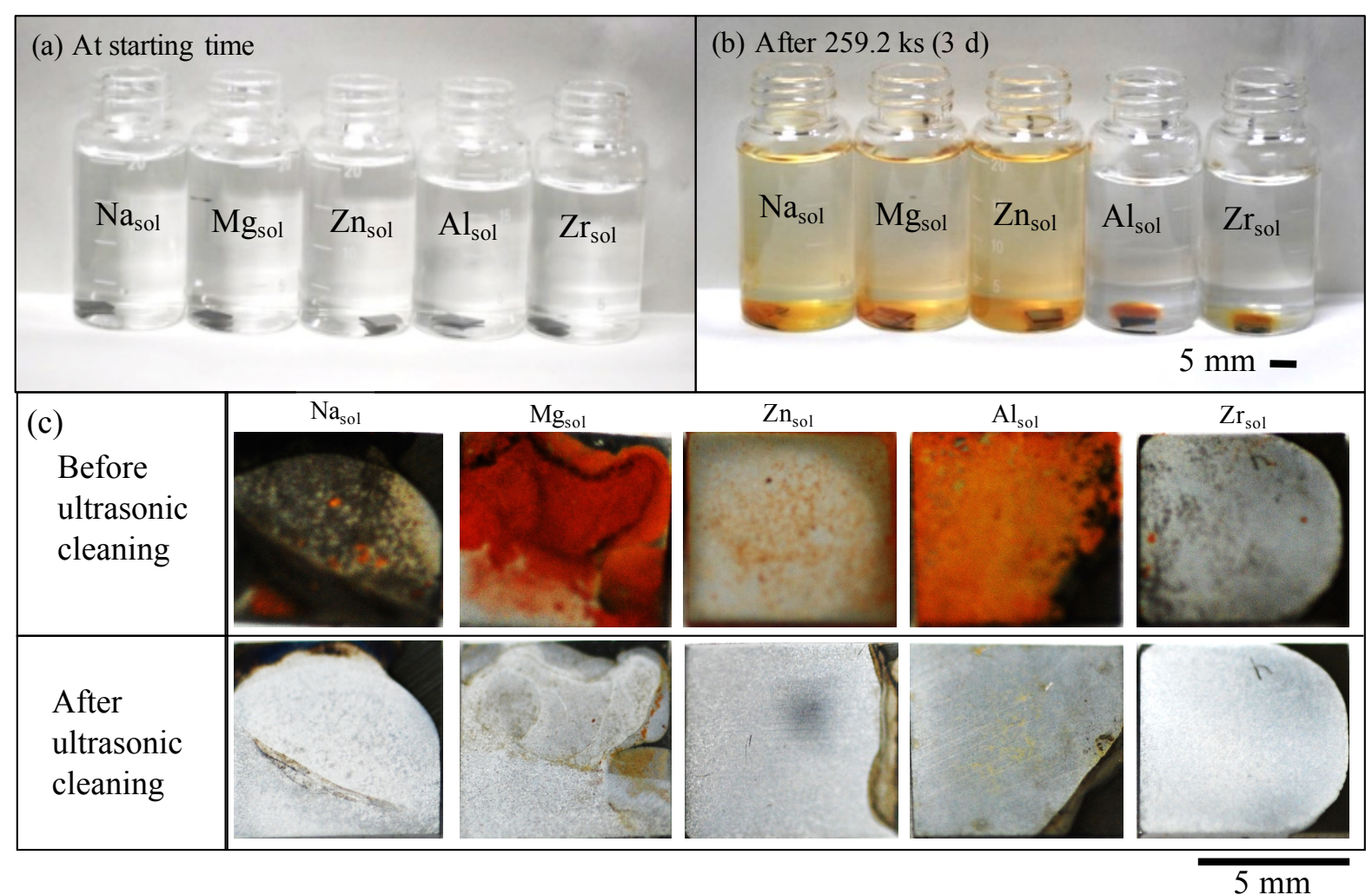

Fig. 3 Appearance of specimens after immersion in the solutions of metal cation (a) at starting time, (b) at immersion for $259.2 \mathrm{ks} \mathrm{(3} \mathrm{d),} \mathrm{and} \mathrm{(c)} \mathrm{surface} \mathrm{images} \mathrm{of} \mathrm{specimens} \mathrm{after} \mathrm{immersion}$ in the solutions for $259.2 \mathrm{ks}$. 


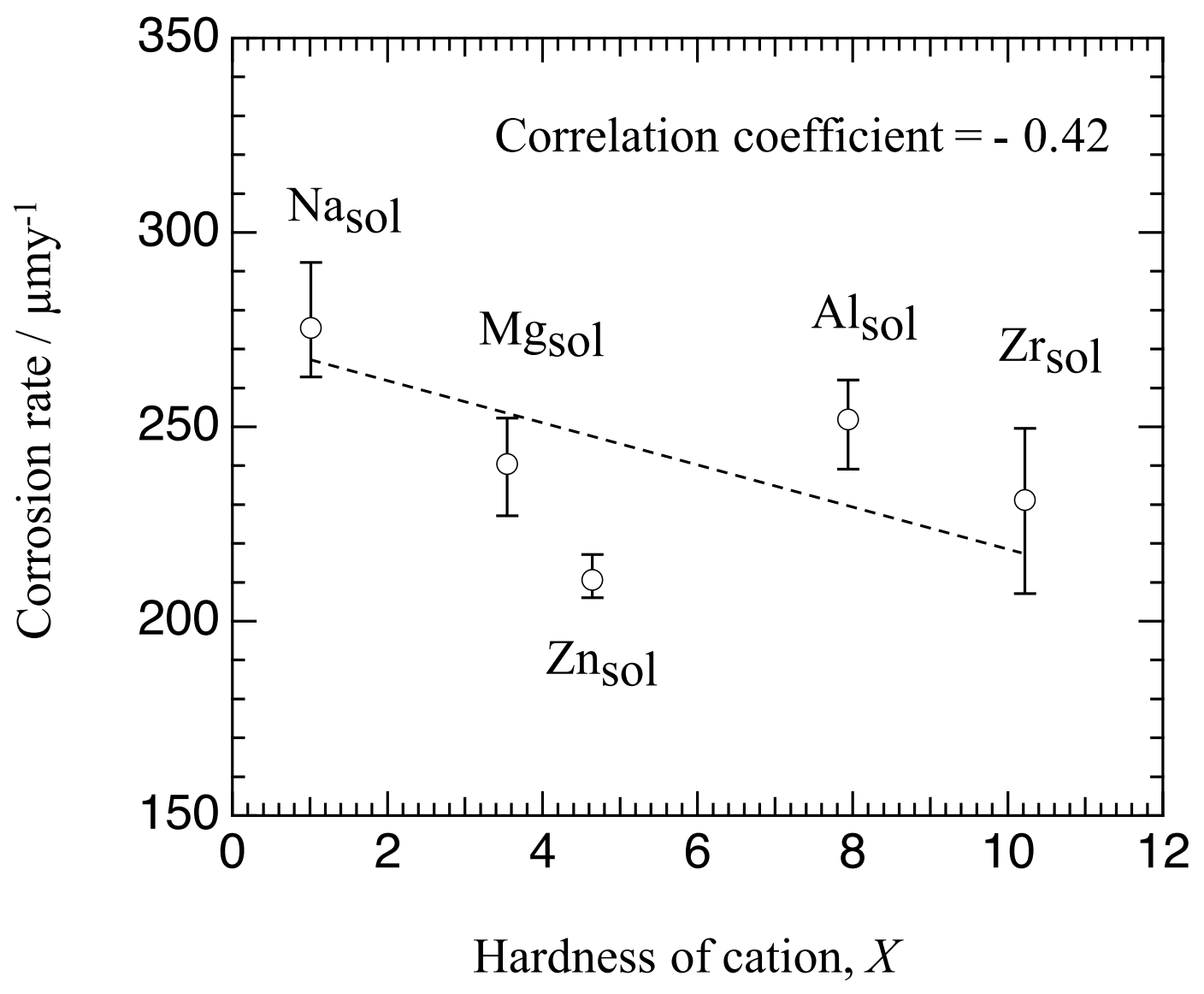

Fig. 4 Corrosion rate as a function of hardness of metal cation, $X$. 

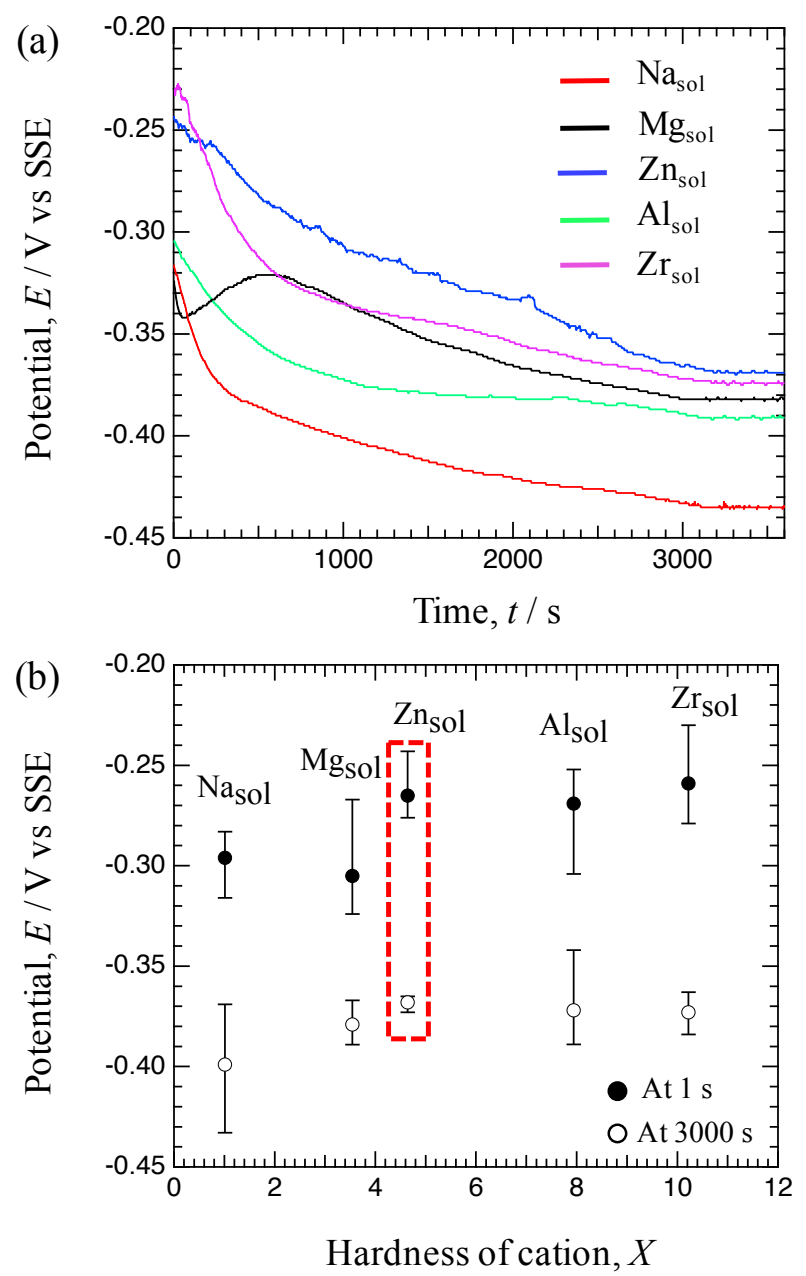

Fig. 5 (a) Open-circuit potential during the immersion tests in different solutions and (b) opencircuit potential of specimen during immersion at $1 \mathrm{~s}$ and at $3000 \mathrm{~s}$. 

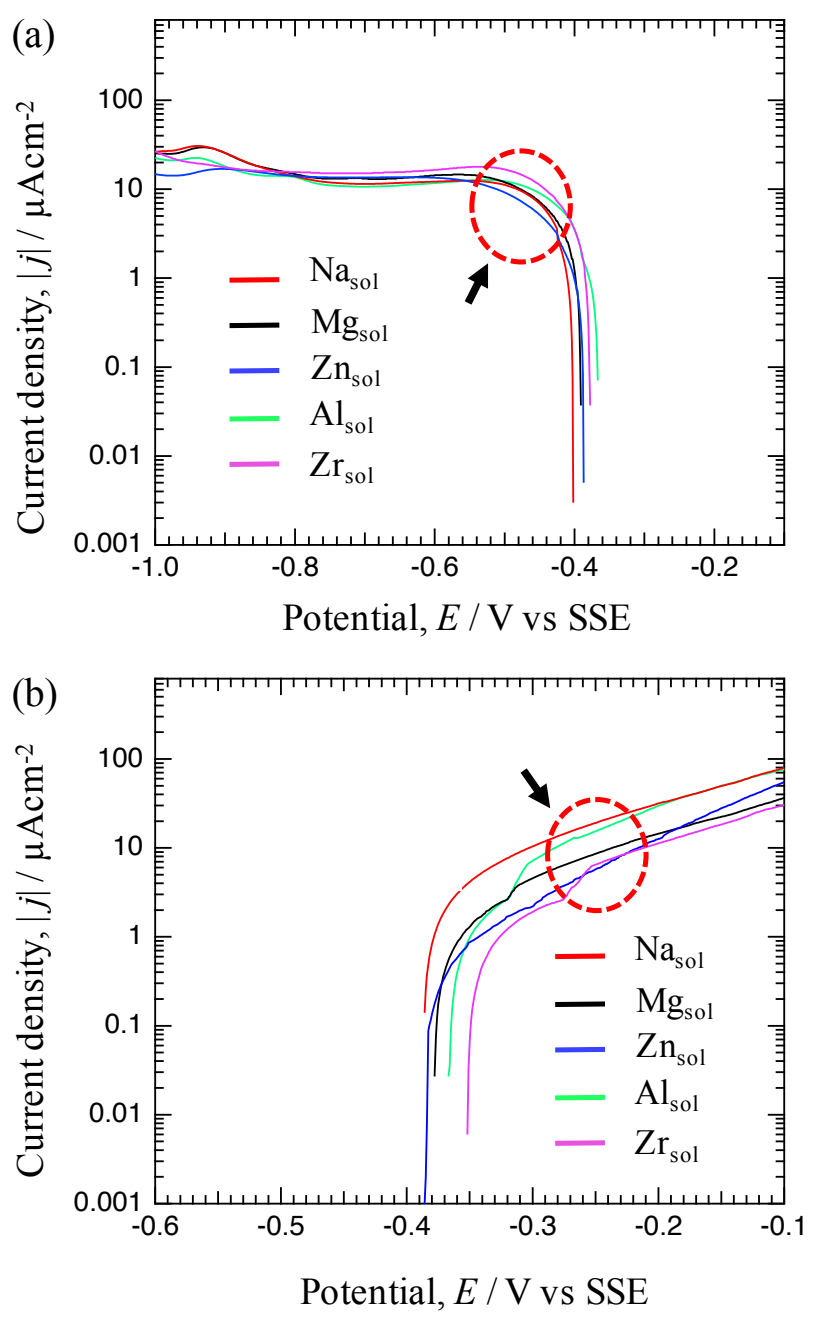

Fig. 6 (a) Cathodic and (b) anodic polarization curves of specimen immersed in the different solutions with metal cations. 

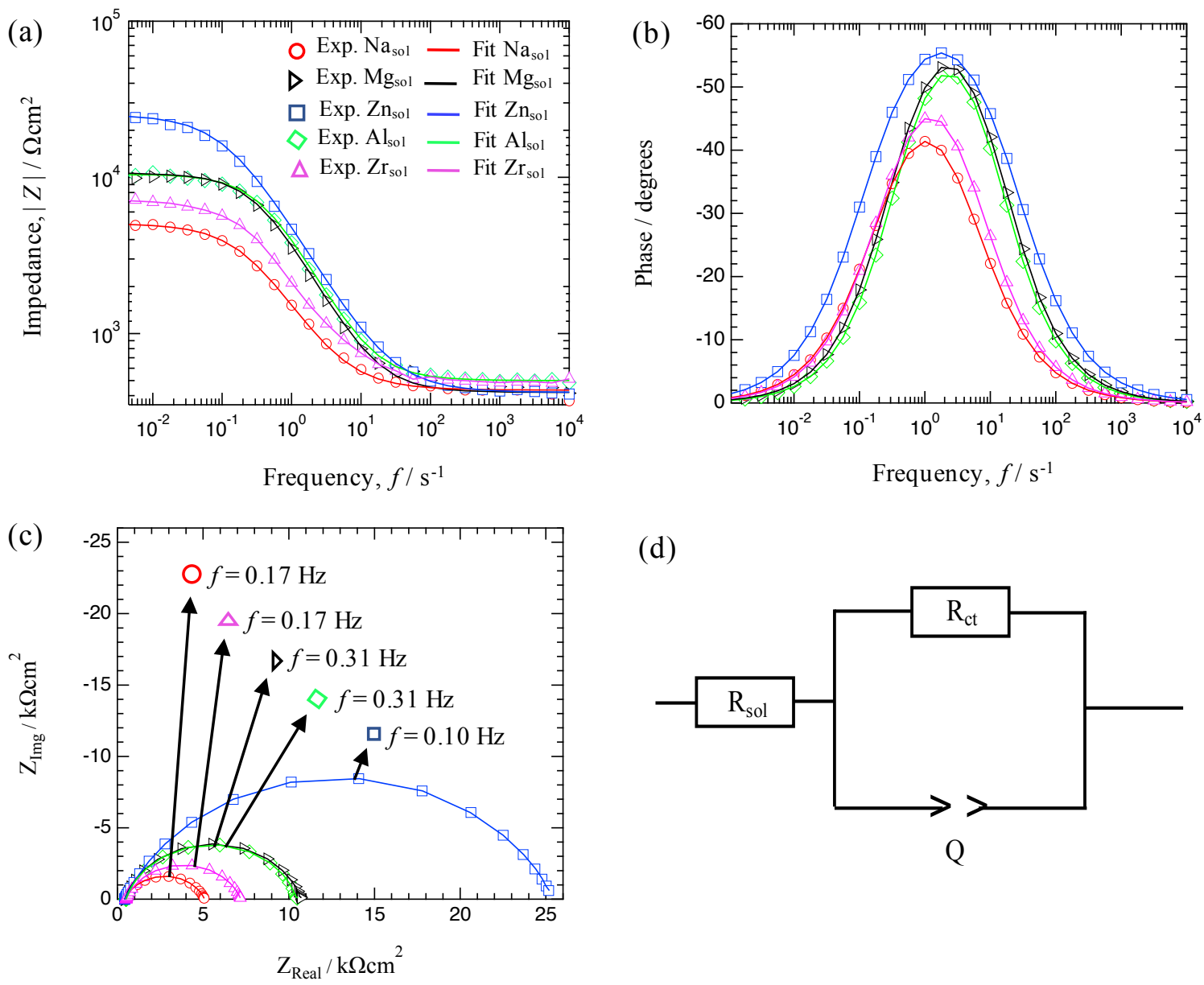

(d)

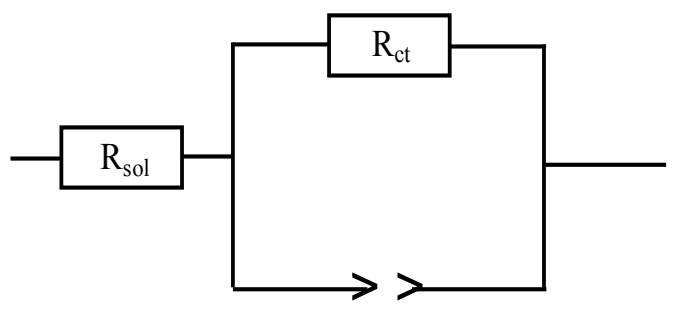

Q

Fig. 7 Results of EIS after immersion for $1 \mathrm{~h}$ in the solutions with metal cations, Bode diagram of (a) Impedance and (b) phase shift plots, (c) Nyquist plots, and (d) equivalent circuit model used to fit the EIS data. 

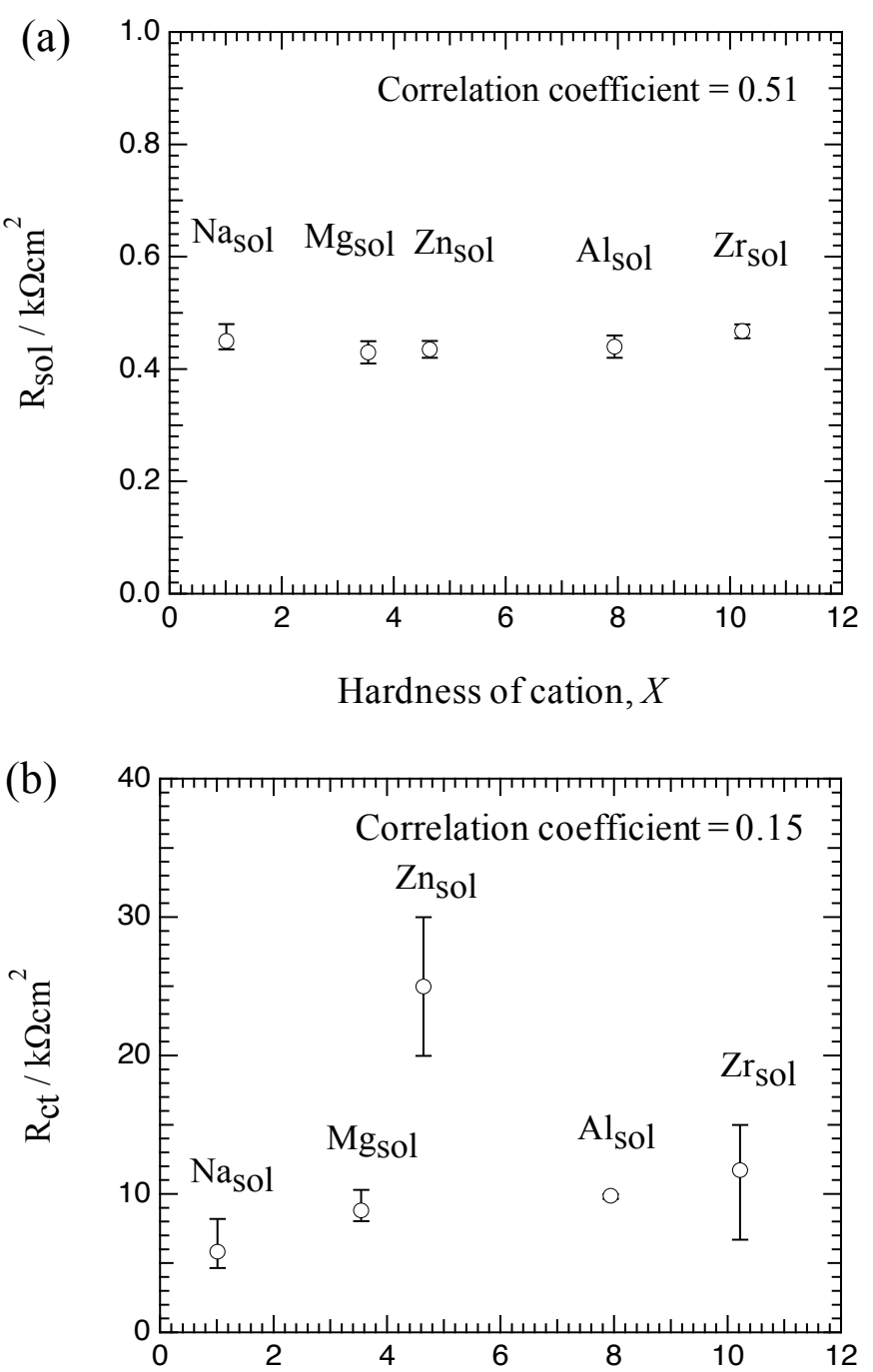

Hardness of cation, $X$

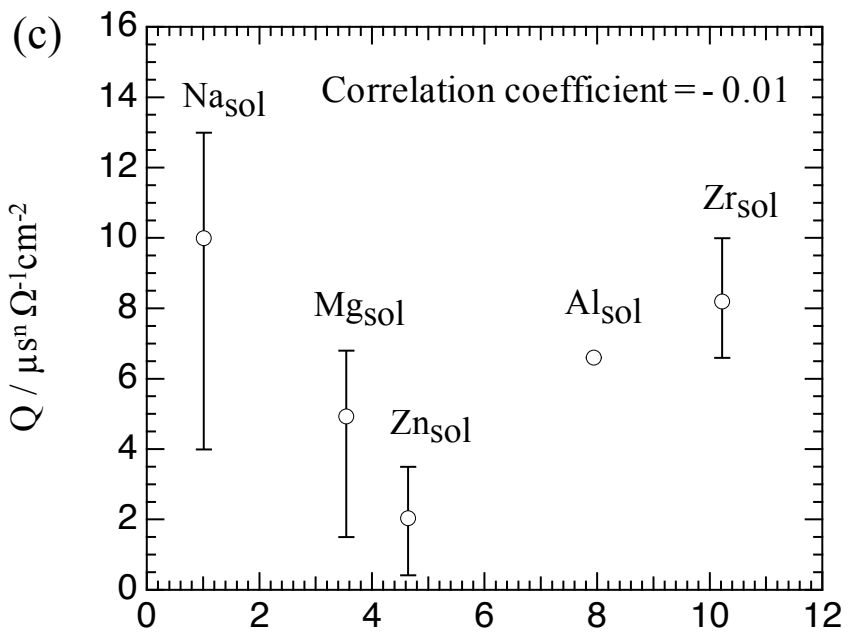

Hardness of cation, $X$

Fig. 8 Changes of (a) $\mathrm{R}_{\text {sol }}$, (b) $\mathrm{R}_{\mathrm{ct}}$ and (c) $\mathrm{Q}$ with $X$ (hardness of metal cation). 

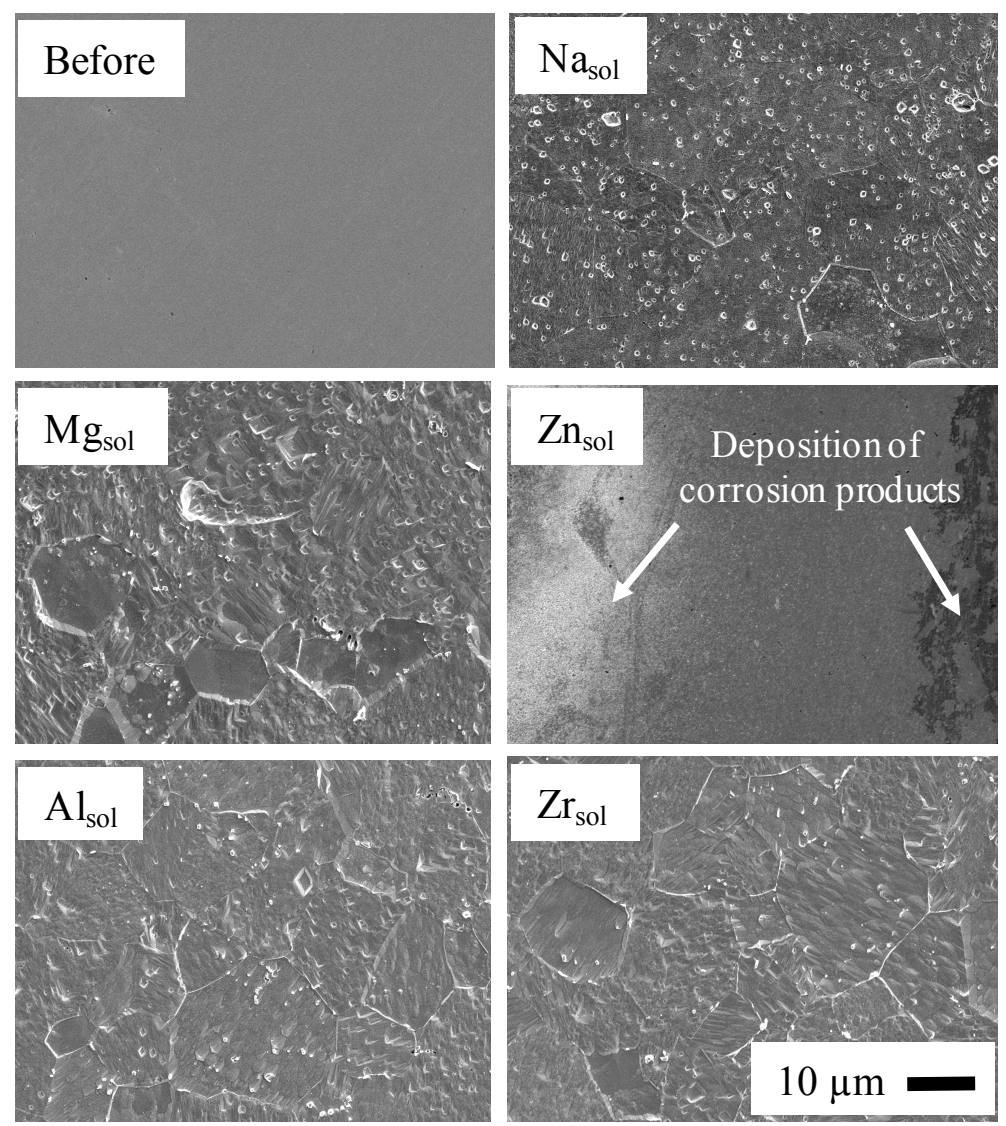

Fig. 9 Surface SEM images of specimen after immersion in the solutions for $259.2 \mathrm{ks}$ at $25^{\circ} \mathrm{C}$. 

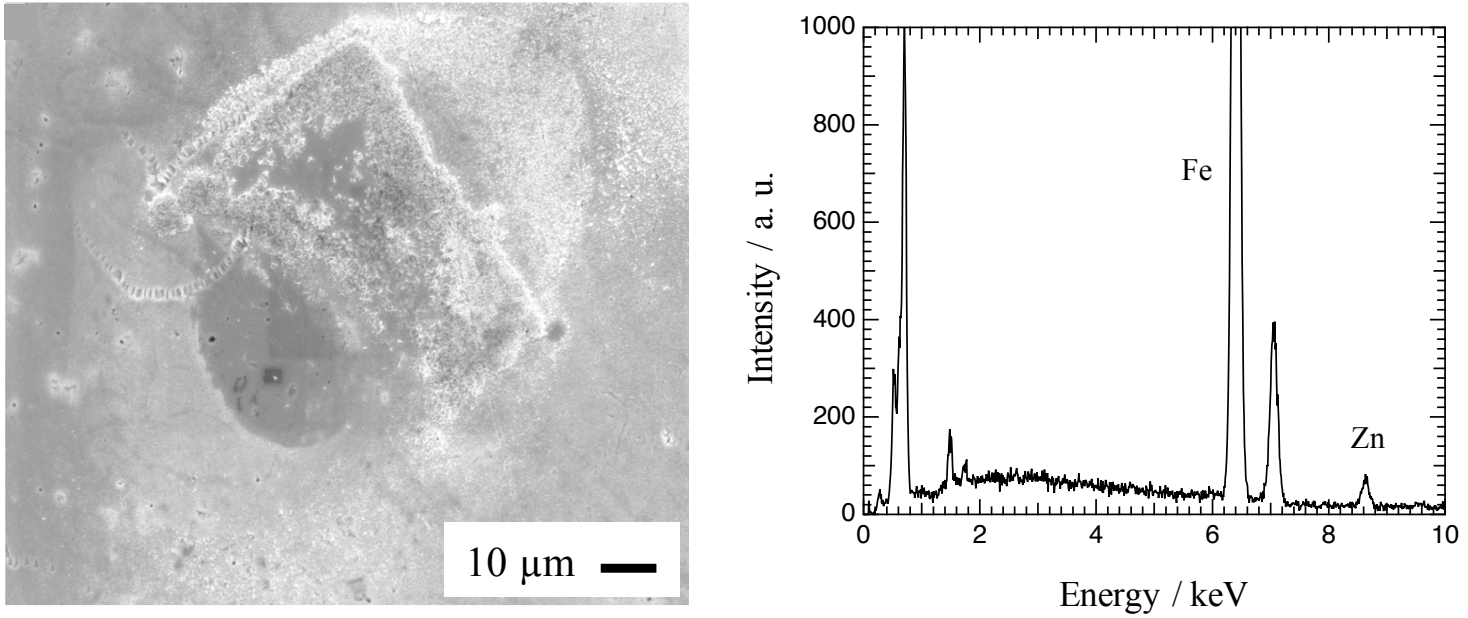

Fig. 10 SEM image of analysis area (left) and EDS results (right) of the specimen surface after immersion in the $\mathrm{Zn}_{\text {sol }}$. 


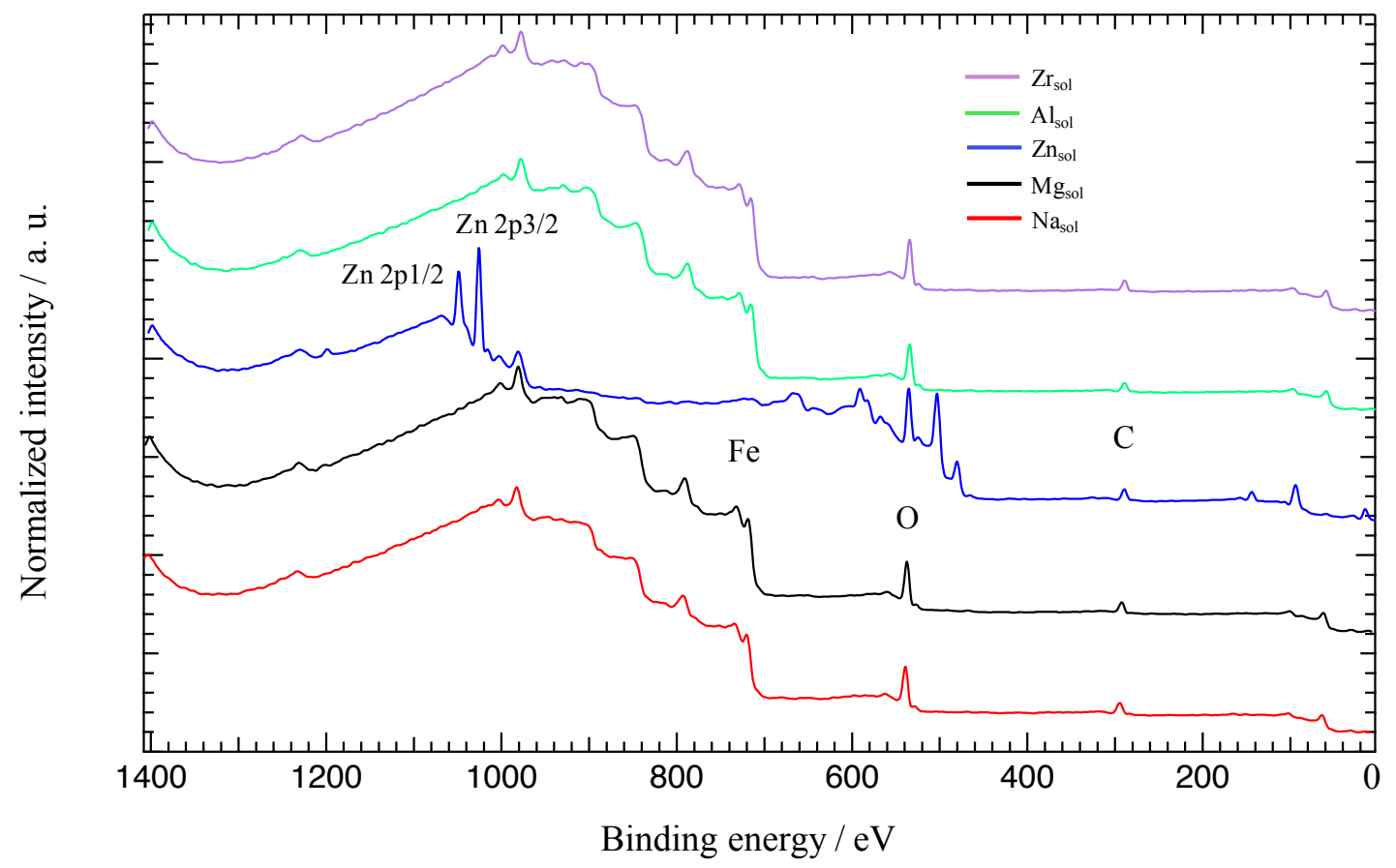

Fig. 11 XPS wide spectra of mild steel surface after immersion in the solutions with metal cations. 


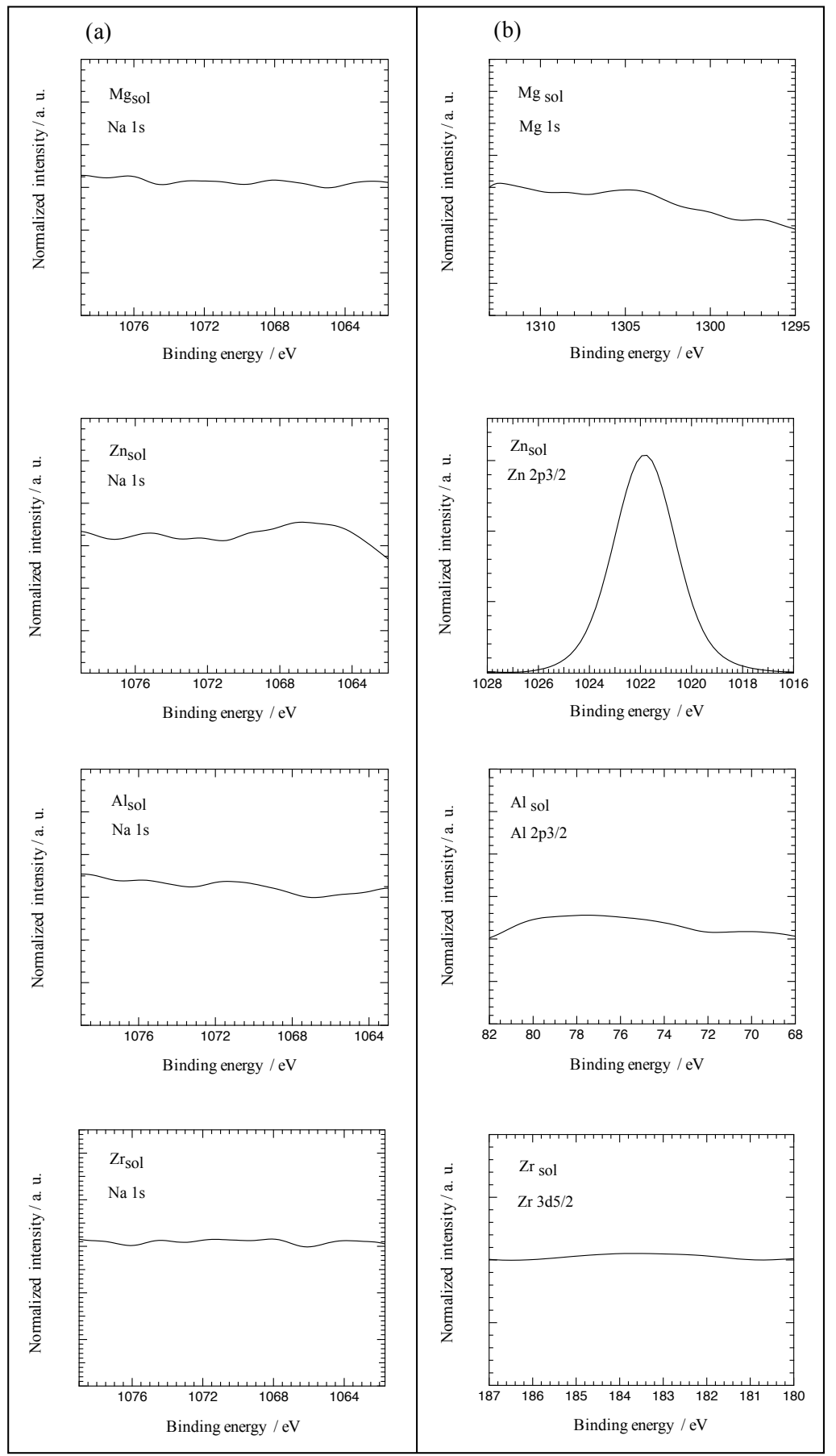

Fig. 12 XPS narrow spectra of (a) Na 1s, and (b) Mg 1s, Zn 2p3/2, Al 2p3/2 and Zr 3d5/2 after immersion in the solutions of metal cations. 

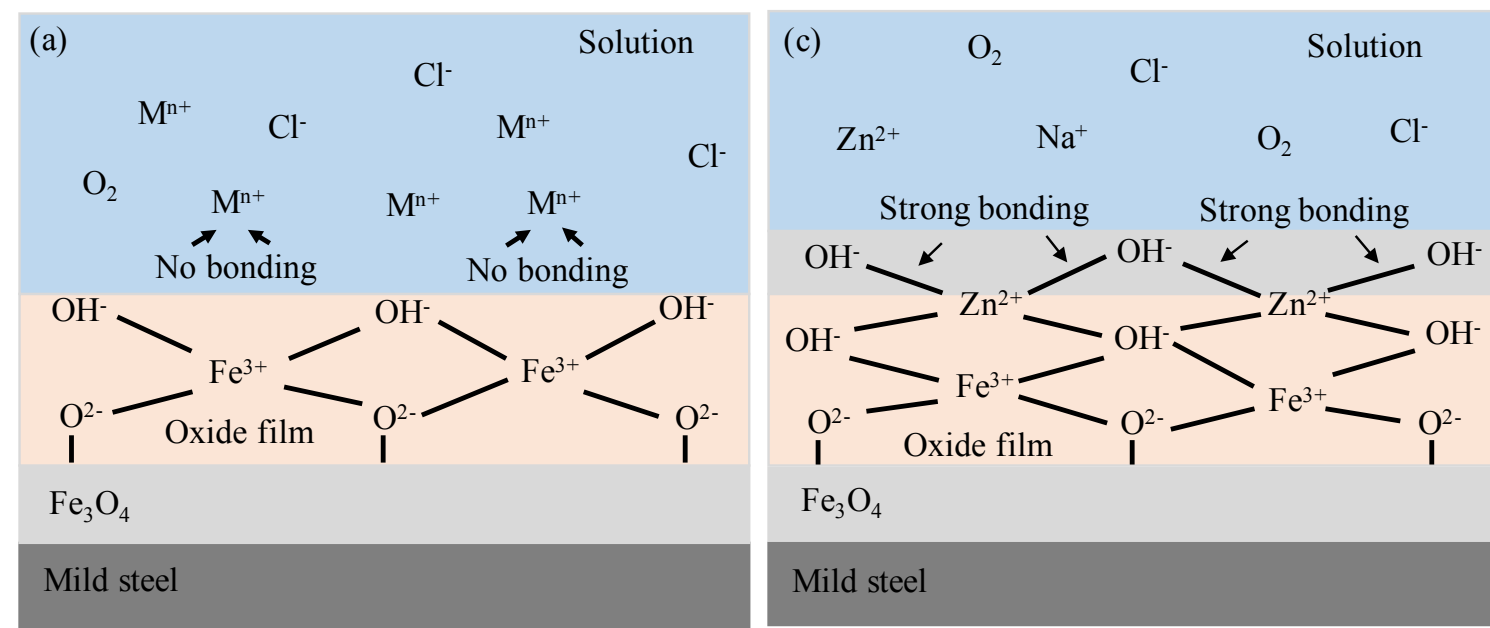
$\mathrm{Fe}_{3} \mathrm{O}_{4}$

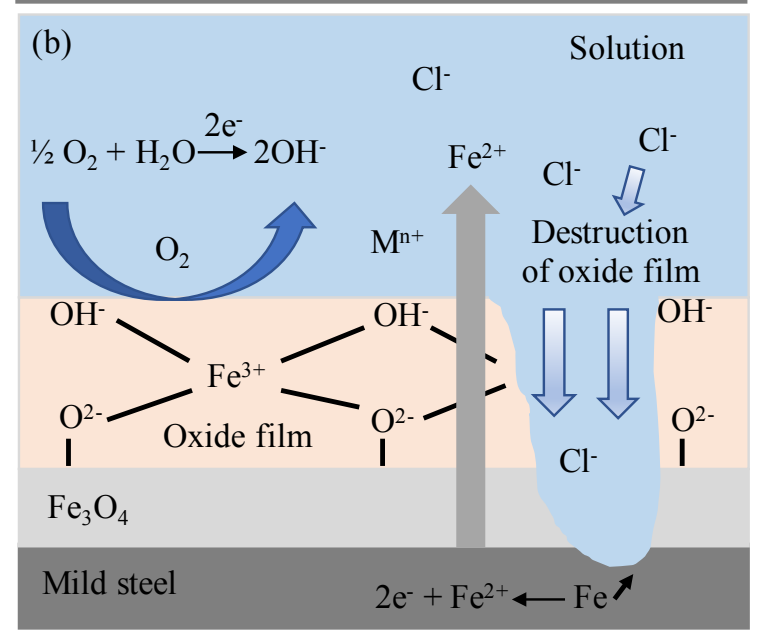

\section{Mild steel}

(d)

$1 / 2 \mathrm{O}_{2}+\mathrm{H}_{2} \mathrm{O} \quad 2 \mathrm{OH}^{-}$

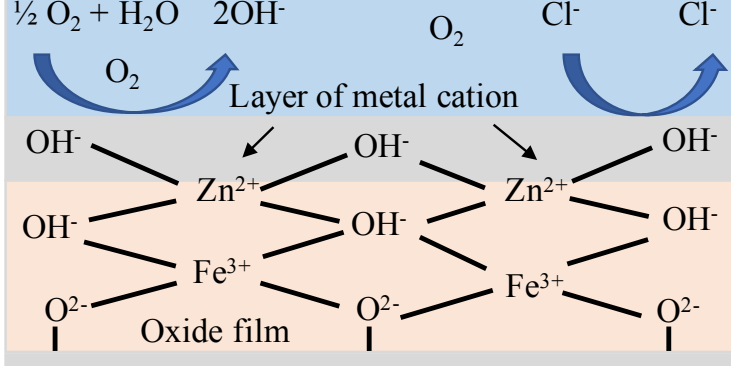
$\mathrm{Fe}_{3} \mathrm{O}_{4}$

\section{Mild steel}

Fig. 13 (a) and (b) possible corrosion mechanism of metal cations $\left(\mathrm{M}^{\mathrm{n}+}=\mathrm{Na}^{+}, \mathrm{Mg}^{2+}, \mathrm{Al}^{3+}\right.$, and $\mathrm{Zr}^{4+}$ ) with the passive film of mild steel in $10 \mathrm{mM} \mathrm{Cl}^{-}$aqueous solution, (c) and (d) possible corrosion inhibition mechanism of $\mathrm{Zn}^{2+}$ with the passive film of mild steel in $10 \mathrm{mM} \mathrm{Cl}-$ aqueous solution. 